\title{
Title \\ Interactions with humans impose time constraints on urban-dwelling rhesus macaques (Macaca mulatta)
}

Authors:

Stefano S. K. Kaburu ${ }^{1}$, Brianne Beisner ${ }^{2,3}$, Krishna N. Balasubramaniam ${ }^{2}$, Pascal

R. Marty ${ }^{2}$, Eliza Bliss-Moreau ${ }^{3,4}$, Lalit Mohan ${ }^{5}$, Sandeep K. Rattan ${ }^{5}$, Małgorzata

E. Arlet ${ }^{6,7}$, Edward R. Atwill ${ }^{2} \&$ Brenda McCowan ${ }^{2,3}$

Address:

${ }^{1}$ Department of Biomedical Science \& Physiology, School of Sciences,

University of Wolverhampton, Wolverhampton, WV1 1LY, United Kingdom

${ }^{2}$ Department of Population Health \& Reproduction, School of Veterinary

Medicine, University of California, Davis, CA 95616, USA

${ }^{3}$ California National Primate Research Center, University of California, Davis, Davis, CA 95616, USA

${ }^{4}$ Department of Psychology, University of California, Davis, Davis, CA 95616, USA

${ }^{5}$ Himachal Pradesh Forest Department, Shimla, Himachal Pradesh, 171002, India

${ }^{6}$ Adam Mickiewicz University, Institute of Anthropology, Poznań Poland

${ }^{7}$ School of Biology, Indian Institute of Science Education and Research (IISER), Trivandrum, Kerala, India

Correspondence: $\quad$ Stefano S. K. Kaburu (s.kaburu@wlv.ac.uk)

ORCID: 0000-0001-7456-3269 
Department of Biomedical Science \& Physiology, School of Sciences, University of Wolverhampton, Wulfruna Street, Wolverhampton, WV1 1LY, United Kingdom.

11

1223 13

14

1524

17

1825

20

21

23

24

2527

26

27

288

29

30

3129

32

33

3430

35

36

37
38

39

40

$41^{32}$

42

43

443

45

46

4734

48

49

5@85

51

52

5336

54

55

5637

57

58

5938

61

62

63

64

65
Time constraints in urban-dwelling macaques 
Keywords: Urban wildlife, Social behavior, Resting, Monitoring, Ethnoprimatology 


\section{Introduction}

Time is a valuable, but limited, resource for animals. Individuals' natural physiological cycles

(e.g., wake/sleep cycle), along with their need to engage in a variety of mutually exclusive activities (e.g., feeding, travelling, socializing) impose strong limitations to the time individuals can allocate to each activity (Dunbar et al., 2009). Historically, researchers have investigated a broad range of environmental, physiological, and ecological factors that can constrain animals' activity budgets, such as day length (Lewis et al., 2004), temperature (Owen-Smith, 1998), seasonal changes (Johansson \& Rowe, 1999), food distribution and quality (Dunbar et al., 2002), reproductive status (Dunbar \& Dunbar, 1988), predation pressure (Johansson et al., 2001), and position in the group (Black et al., 1992). In comparison to these effects, less attention has been paid to the impact of anthropogenic factors, and in particular human-animal interactions, on animals' time budgets. This is despite increasing recognition among ecologists that many urban-dwelling species come into direct contact with humans, and human impact on the environment is posing novel and sometimes unpredictable selective pressures on the biology and behavior of wildlife (Vitousek et al., 1997; Fuentes, 2012). Since animals' survival strongly depends on their ability to manage the amount of time they allocate to each activity (Dunbar et al., 2009), understanding how interactions with people may constrain animals' activities can shed important light on how humans can affect their survival. For this reason, here we examine how interactions with humans and the time spent monitoring human activity influence resting and time spent engaging in social interactions in urban-dwelling rhesus macaques (Macaca mulatta).

A wide body of research has extensively shown how a variety of ecological and social variables negatively impact animals' time budgets. High temperatures, for instance, force many animals to increase their resting time, thereby reducing their time available to satisfy their other needs (e.g., feeding, socializing; Aublet et al., 2009; Korstjens et al., 2010). Work in ungulates and birds has shown that individuals who are positioned on the edge of the group spend more time engaging in vigilance-related 
behaviors, which reduces the amount of time they can allocate to foraging (e.g., Murton et al., 1971; Lipetz \& Bekoff, 1982; Petit \& Bildstein, 1987; Keys \& Dugatkin, 1990; Black et al., 1992). Furthermore, for species who live in social groups, a substantial amount of time needs to be devoted to social interactions in order to maintain cohesion within the group, which limits the time animals can spend in other activities like resting and foraging (Dunbar, 1992; Dunbar et al., 2009). A reduction of resting time and time spent in social interactions in the face of time constraints can have long-term consequences on animals' fitness. Resting time, for instance, is important for digestion, energy recovery, and thermoregulation (Herbers, 1981; Korstjens et al., 2010; McFarland et al., 2014), while social interactions (at least for group-living animals) play an important role in animals' ability to cope with environmental and social stressors (Silk et al., 2003; Frère et al., 2010; Formica et al., 2012). This can explain why time constraints tend to affect animal's group size (Chapman et al., 1995; Korstjens et al., 2006; Pollard \& Blumstein, 2008), geographic distribution (Dunbar, 1992; Korstjens et al., 2010, 2018; Dunbar \& Shi, 2013), reproductive success (Siikamäki, 1998), mate choice (Backwell \& Passmore, 1996), and, ultimately, survival (Dunbar et al., 2009). Consequently, animals are expected to make careful decisions when deciding how much time to devote to each activity in order to increase their chances of survival (Dunbar et al., 2009).

In comparison to the aforementioned selective pressures, the impact of humans and anthropogenic factors, such as the availability and distribution of anthropogenic food or the destruction and fragmentation of wildlife habitat, on animals' time budgets has been understudied, and has received only recent attention. Yet, greater numbers and diversities of species are coming into contact with anthropogenic environments as human populations expand rapidly. In the last 100 years the world's human population has experienced an increase in size three times higher than during its entire prior history, increasing from 1.5 billion in 1900 to 7 billion in 2010 (Roser \& Ortiz-Ospina, 2018). Accumulating evidence demonstrates how this rapid increase in human population generates rapid 
environmental and ecosystem changes at global scales, making human impact an ecological force that needs to be reckoned with (Vitousek et al., 1997; Fuentes, 2012). Human activity may impact animal energetics, fitness and survival by influencing their activity budgets (Szott et al., in press; Lott \& McCoy, 1995; Lehmann et al., 2010). They may do so in different, sometimes contrasting ways, and work to date has yielded mixed results regarding the effect of anthropological disturbance on animals' activity budgets. Some studies have revealed that humans have a disruptive effect on wildlife activities, imposing strong time constraints. Proximity to humans, for example, can increase animals' vigilance or monitoring behavior at the expense of other activities, such as feeding, resting or socializing (e.g., India rhinoceros, Rhinoceros unicornis: Lott \& McCoy, 1995; boreal woodland caribou, Rangifer tarandus caribou: Duchesne et al., 2000; Barbary macaque, Macaca sylvanus: Majolo et al., 2013; rhesus macaque, Macaca mulatta: Kaburu et al., 2019; long-tailed macaque, Macaca fascicularis: Marty et al., 2019). Furthermore, in areas degraded by human activities, animals might be forced to increase their travel time, thereby decreasing their resting and social time, either in order to avoid humans or because natural food sources become scarce (red deer, Cervus elaphus: Grover \& Thompson, 1986; lion-tailed macaque, Macaca silenus: Menon \& Poirier, 1996; tonkean macaque, Macaca tonkeana: Riley, 2007). In contrast, other studies reveal that animals that live and thrive in an anthropogenic environment tend to spend more time resting and socializing than groups living in less anthropogenic areas (e.g., vervet monkey, Chlorocebus pygerythrus: Saj et al., 1999; Thatcher et al., 2019; Barbary macaque, Macaca sylvanus: El Alami et al., 2012; rhesus macaque: Jaman \& Huffman, 2013; assamese macaque, Macaca assamensis: Koirala et al., 2017; long-tailed macaque: Ilham et al., 2018). Such beneficial effects may be due to reliance on anthropogenic foods that tends to be higher in calories, more abundant, and more digestible than natural foods (Forthman-Quick, 1988; Rode et al., 2006; Riley et al., 2013; McLennan and Ganzhorn, 2017), and researchers argue that in this condition animals can spend less time feeding, and consequently increase their time spent resting and/or socializing (Jaman \& Huffman, 2013). 
There are, to date, two major gaps in the literature examining anthropogenic influence on animal activity budget. First, extant work has largely focused on indirect human impact on animals' activities, by comparing, for instance, wildlife behavior in geographic areas that are characterized by high versus low human impact (e.g., Saj et al., 1999; Jaman \& Huffman, 2013; but see Marty et al., 2019). However, across a variety of interfaces, from rural to urban areas, people often engage in a variety of direct interactions with wildlife (e.g., mutual aggression, human provisioning) that may have different impacts on animals' behavior (McCarthy et al., 2009; Fuentes, 2012; Maréchal et al., 2016). Food provisioning by tourists, for instance, has been shown to increase aggression and contact time in Mareeba rockwallabies (Petrogale mareeba: Hodgson et al., 2004) and to reduce social grooming in rhesus macaques (Ilham et al., 2018). However, the extent to which direct interactions between humans and wildlife can impact wild animals' activity budget is not well understood. Second, the majority of studies, to date, have examined how anthropogenic factors may impact animals' activity budget at the group level (e.g., Saj et al., 1999; Jaman \& Huffman, 2013). In comparison, few studies have investigated individual differences in the way animals modify their time budgets in response to anthropogenic factors (e.g., Marty et al., 2019). Overall, addressing how human behavior affects animals' activity budget at individual level may provide important insights on how human pressure can differently affect individual animals' health and fitness, by directly altering the time they spend in the various activities.

Here we test whether direct interactions with humans either constrain animals' activity budgets (time constraints hypothesis) or free up the time they can allocate to resting and social interactions (free time hypothesis) in an urban-dwelling population of rhesus macaques. Rhesus macaques inhabit a variety of interfaces, from agricultural areas to cities and temples, resulting in a close proximity between macaques and humans (Chauhan \& Pirta, 2010a; Southwick \& Siddiqi, 2011; Beisner et al., 2015). To date, studies have shown that such close proximity leads to frequent interactions between the two species, which can take both potentially negative (e.g., mutual aggression) and positive (e.g., humans 
provisioning the macaques) forms (Chauhan \& Pirta, 2010a, b; Beisner et al., 2015). However, little is $\stackrel{6}{100}$ 8

known about whether and how such interactions with humans may impact macaque activity budgets, including affiliative social behaviors like grooming, despite well-documented evidence that affiliative social behaviors are associated with critical health and fitness benefits in group-living animals (Silk et al., 2003). For example, across a broad range of animals, individuals who have strong social relationships and support have been found to exhibit lower chronic stress levels and improved immune function (Young et al., 2014; Kappeler et al., 2015).

We focused on social grooming as a measure of social interactions since this is the most common affiliative behavior in non-human primates (NHPs). The amount of time NHPs spend grooming (which can occupy up to $20 \%$ of their daily time budget; Henzi and Barrett, 1999) often exceeds individuals' hygienic needs (Dunbar, 1991), suggesting that social grooming plays an important role in establishing and maintaining social relationships and group cohesion (Henzi \& Barrett, 1999; Dunbar, 1988, 2010), which ultimately affects individuals' fitness (Silk et al., 2003). Therefore, any human-induced time constraint imposed on social grooming can potentially have long-term consequences for animal's health, social life and reproductive success (Dunbar, 1992; Dunbar et al., 2009).

Under the time constraints hypothesis, we predict that interactions with people reduce macaques' resting and grooming time. Furthermore, given that we have previously shown that among urbandwelling long-tailed macaques individuals who monitored human activity more frequently spent less time grooming (Marty et al., 2019), we also test whether rhesus macaques who monitor more human activity spend less time resting and grooming. Rates of monitoring human activity and interacting with people may be related because macaques may monitor human activity in order to decide how or whether to interact with specific people. Macaques may monitor human activity because people can be a source of threat and, or a source of resources (e.g., food). That is, people can pose either a real or potential threat to the macaques and therefore cause the animals to frequently avoid humans (Chauhan \& Pirta, 2010a, 
b; Priston \& McLennan, 2013). Alternatively, macaques are frequently provisioned by people and some macaques beg for food, investigate people's belongings or steal objects in order to barter the stolen item 8

for food (Beisner et al., 2015; Brotcorne et al., 2017; Kaburu et al., 2019). To determine the nature of the relationship between rates of interaction with humans and monitoring of human activity, as two potentially interdependent sources of time constraints, we first tested whether macaques' monitoring time was affected by total rates of human-macaque interactions as well as by four specific types of interactions: (1) human-to-macaque aggression, (2) macaques avoiding people in a non-aggressive context (e.g., a person walking by or approaching the macaque), (3) humans providing food to the macaques and (4) macaques initiating non-aggressive interactions with people (prediction 1a), We then assessed whether total rates of human-macaque interactions and the four above-mentioned specific types of human-macaque interactions significantly reduced macaques' resting (prediction $1 b$ ) and grooming time (prediction 1c). As part of prediction 1c, we tested whether grooming time was significantly affected by monitoring time. We did not test whether time spent monitoring affected macaques' resting behavior because the two activities were not mutually exclusive (i.e., macaques could monitor human activity while resting), which is an assumption of the time constraints model (Dunbar, 1992; Dunbar et al., 2009).

Alternatively, under the free time hypothesis, we predict that individuals who forage more on anthropogenic food spend more time resting (prediction 2a) and in social grooming (prediction 2b), on the premise that anthropogenic food is more caloric and more digestible than natural food. Our predictions and models are summarized in Figure 1.

\section{Materials and Methods \\ Study site and subjects}


Observational protocols were approved by the Institutional Animal Care and Use Committee of the University of California, Davis. These protocols were designed in consultation with the Himachal Pradesh Forest Department and complied with the legal requirements of India.

The study was conducted in the city of Shimla $\left(31^{\circ} 05^{\prime} \mathrm{N}-077^{\circ} 10^{\prime} \mathrm{E}\right)$ between July 2016 and February 2018. Data were collected from a total of 127 macaques (37 adult males and 90 adult females) from three groups living in proximity to Jakhoo Temple, a Hindu temple located on the highest peak of Shimla at 2,500m above the sea level. The macaques' home range comprises both the temple area, where most of the human-macaque interactions occurred, and the surrounding forested area (see Kaburu et al., 2019 for more details on the study site). Macaques, therefore, had access to both anthropogenic and natural food.

\section{Behavioral data collection}

SSKK and six research assistants collected behavioral data from all adult males and females of the groups using 10-min focal animal sampling (Altmann, 1974), between 9:00 and 17:00, five days a week (reliability, Cohen's k > 0.85). Observers randomized the order by which focal animals were sampled on a daily basis prior to data collection, aiming to collect two focal sessions per animal per week, one in the morning and one in the afternoon. If the focal animal went out of sight for more than 3 minutes, the observation was aborted. Data from aborted observations were maintained in the database and used for the data analysis, but observers attempted to re-do a complete focal sample on that animal at the next available opportunity. At the end of the study, we collected a total of 1494 hours of observations, with a mean $( \pm \mathrm{SD})$ hour of observation per individual of $11.8( \pm 5.4$; median $=10.8)$.

During focal sessions, we recorded all continuous interactions the focal animals had with both humans and other macaques. When recording human-macaque interactions, we collected data on aggression (e.g., a person threatening or attacking a macaque, or vice versa), food provision (e.g., a 
person providing food to the macaques), submission (e.g., a macaque avoiding a person who is walking by or approaching the monkey, or vice versa), and other types of physical interactions between the focal 8 2931 10

animal and humans, such as macaques investigating a person's pocket or bags (a short version of the ethogram is available in table S1, while a more extended ethogram can be found in Kaburu et al., 2019). When the focal animal interacted with a person, we recorded information on the time stamp in which the interaction occurred, as well as the age/sex category of the person involved (i.e., man, woman or child). For interactions between the focal animal and other macaques, we recorded data on both aggression (e.g., chase, bite, slap, threat) and affiliation (e.g., grooming, huddling), collecting data on both the identity of the monkey the focal animal was interacting with, the time when the interaction occurred and, for grooming and huddling only, the duration of the interaction. Finally, every two minutes we used instantaneous sampling (Altmann, 1974) to record the focal animal's activity, specifically whether the animal was 1) foraging on anthropogenic food, 2) foraging on natural food, 3) grooming, 4) socializing (i.e., any affiliative or aggressive social interaction, except for grooming), 5) moving or, 6) resting.

We defined anthropogenic food as any human-made food item, including fruits that are normally cultivated by people (e.g., bananas) and not readily available in the animals' environment. Macaques can access anthropogenic food either by directly interacting with people (through human provisioning for instance) or by foraging on garbage or discarded food. Among the study groups, macaques tended to obtain anthropogenic food from indirect sources (e.g., discarded food) rather than via direct interaction with humans. Thus, human provisioning and non-aggressive interactions initiated by the macaques towards humans explain only about $12 \%$ and 5\%, respectively, of macaques' rates of foraging on anthropogenic food (human provision: $\mathrm{F}(1,122)=17.42$, $\mathrm{p}<0.001, \mathrm{R}^{2}=0.117$; non-aggressive macaque-tohuman behaviors: $\left.\mathrm{F}(1,122)=7.446, \mathrm{p}=0.007, \mathrm{R}^{2}=0.050\right)$. On the other hand, natural food was defined as any food item naturally growing in the environment (e.g., grass, leaves). During instantaneous sampling, we also noted whether the focal animal was monitoring human activity, if s/he was looking in the 


\section{Data analysis}

Dominance rank

From the dyadic dominance interactions with decided winner-loser outcome, we calculated dominance rank using the Perc package in R (Fujii et al., 2015), which calculates dyadic dominance relationships on the basis of both direct interactions and multiple indirect pathways (for more details see Fushing et al., 2011). In order to control for group size, we followed previous approaches (e.g., Rhine et al., 1989) and standardized dominance rank as follows:

$$
1-\frac{(\operatorname{Rank}-1)}{(N-1)}
$$

Where $N$ represents the number of focal animals in the group. Standardized dominance rank values range between 0 (bottom-ranking animal) and 1 (top-ranking animal).

Test of the time-constraint hypothesis

To test our predictions, we used the glmer.nb function in the 'lme4' package in $\mathrm{R}$ to run Generalized Linear Mixed Model (GLMM) analysis. To test whether human-macaque interactions predicted macaque's monitoring of human activity (prediction 1a), we fit a GLMM model set (with negative binomial distribution) to the outcome variable: the count of scans in which macaques were monitoring humans. In the model, total rates of human-macaque interactions as well as four specific types of interactions, namely human-to-macaque aggression, macaques avoiding humans, humans providing food to macaques, and macaques initiating non-aggressive interactions with humans, were 
included as predictors. We included as an exposure variable each macaque's total number of scans, as an individual's monitoring depends on how long the focal animal was observed (Table 1).

To test the effects of monitoring and human-macaque interactions on resting and grooming time (predictions $1 \mathrm{~b}$ and 1c, respectively), we ran two sets of GLMM analyses (both with negative binomial distributions) on two outcome variables: the number of scans in which each macaque was (1) resting and (2) grooming. For each outcome variable, we fit as predictors both the total rates of human-macaque interactions and the four specific types of human-macaque interactions mentioned above. For models of the grooming outcome variable, we also included monitoring rate as a predictor. Finally, we included the total number of scans as an exposure variable for all models (Table 1).

\section{Test of the free time hypothesis}

To test whether macaques who foraged more on anthropogenic food spent more time resting and grooming (predictions $2 \mathrm{a}$ and $2 \mathrm{~b}$, respectively), we fit two GLMM model sets by setting the number of scans in which the animal was scored resting or grooming as outcome variables in separate models, with the rates of foraging as predictor and total number of scans as exposure variable. Given that we were interested in assessing whether the proportion of time spent foraging on human food with respect to the total amount of time spent foraging significantly impacted animals' resting and social time, we calculated foraging rates by dividing the total number of scans in which the animal was scored foraging on anthropogenic food by total number of scans in which the animal was scored feeding on both natural and anthropogenic food (Table 1).

In all the models, we included individuals' sex and rank and their interactions with the other predictors as previous work has shown that, in rhesus macaques, these variables may affect both resting and grooming time, as well as rates of human-macaque interactions (Jaman \& Huffman, 2013; Beisner et al., 2015; Snyder-Mackler et al., 2016). Additionally, we set group membership as a random factor to 
control for non-independency of data collected from members of the same group. For all models, we ztransformed continuous predictors (i.e., both rates of human-macaque interactions, monitoring and dominance rank) in order to facilitate comparisons between effect sizes of variables that were on different scales (Gelmann, 2008). Furthermore, we ran model diagnostics to check that all the model assumptions, including collinearity between predictors, homogeneity and normality of residuals of the models were respected. We used cook's distance to assess the presence of influential observations, and this analysis revealed the presence of three outliers, that were excluded from all the analyses, giving a final sample size of $\mathrm{N}=124$ macaques. We took an information theoretic (I-T) approach to model selection, using AIC scores from each model to select a candidate set of models for each prediction. The candidate model set included all models with $\triangle \mathrm{AIC}<2$ compared to the best model, because all such models can be considered equally good (Burnham et al., 2011). Further, we applied the concept of parsimony when assembling the candidate model set, and we excluded a model if there was a simpler model (with fewer predictors) with a better AIC score (Richards et al., 2011). Here we present only the candidate model set while all the models can be found in the Supplementary Material (Table S2). Table 1 summarizes our GLMM models.

\section{Results}

\section{Descriptive statistics}

We recorded a total of 3993 interactions between humans and macaques, and found large individual differences among macaques in both their rates of interactions with humans, and in their activity budgets (Table 2). Among the different types of human-macaque interactions examined, we found that macaques' avoidance of people was the most common type of interaction while nonaggressive macaque-to-human behaviors were the least common (summarized in Table 2). 


\section{Test of the time-constraint hypothesis}

Monitoring rates (prediction 1a)

Our GLMM analysis showed that macaques' monitoring of human activity was best predicted by an interaction between the rates of all human-macaque interactions and either sex or rank (Table 3 ). This result indicates that macaques who more frequently monitored human activity interacted more often with people, and that this effect was stronger for females and low-ranking macaques. (Figures 2 and 3 ).

\section{Resting rates (prediction $1 b$ )}

We found that resting time was best predicted by an interaction between rank and total rates of human-macaque interactions, as well as by rates of human provisioning (Table 4) supporting prediction 1b. Macaques who interacted more frequently with people spent less time resting, with a slightly greater effect for low-ranking individuals (Figure 4). Likewise, macaques who were provisioned more frequently spent less time resting (Figure 5).

\section{Grooming rates (prediction 1c)}

Macaques' grooming time was best predicted by the model that included the three-way interaction between rates of all human-macaque interactions, sex and rank (prediction 1c) (Table 5). More specifically, macaques who interacted more frequently with people significantly reduced grooming time, although this negative relationship was absent for subordinate females (Figure 6).

\section{Test of the free time hypothesis}


Contrary to the free time hypothesis we found a negative relationship between resting time and the rates of feeding on anthropogenic food - that is, as rates of foraging on anthropogenic food increased, resting time decreased- and there was no relationship between rates of feeding on anthropogenic food and grooming time, as indicated by the best model which included only sex and rank (Table 6). In other words, we found no evidence in support of the free time hypothesis: foraging on human food did not lead macaques to spend more time resting or socializing.

\section{Discussion}

Recently, human activity and anthropogenic landscapes have imposed novel socioecological selective pressures on the behavior and fitness of wildlife populations. In this light, our study sought to test two conflicting hypotheses related to whether and how interactions with humans impact the activity budget of an urban-dwelling non-human primate, the rhesus macaque. Our results showed that macaques' interactions with humans strongly impacted macaques' resting and social time, thereby providing support for the time constraints hypothesis. More specifically, we first showed that macaques who spent more time monitoring human activity also interacted more frequently with people. We then found that macaques who interacted more frequently with people reduced both their resting and grooming time. Interestingly, the negative relationship between human-macaque interactions and grooming rates was not present in low-ranking females. By contrast, we did not find any evidence in support of the free time hypothesis; macaques' consumption of human resources did not affect their resting or social time.

These results add to only a handful of studies to date that have shown that human disturbance can negatively impact wildlife activity budget, including social behavior. Asian rhinoceros, for instance, increase their vigilance time and reduce their feeding time in the presence of tourists (Lott \& McCoy, 1995). Menon \& Poirier (1996) showed that lion-tailed macaques under heavy human disturbance displayed more foraging, and less resting and socialization compared to populations under no human 
pressure. The authors argued that this was likely due to the human-induced low availability of key food items animals experienced. Lehmann and colleagues (2010) showed that human-induced global warming 8

can force great apes to spend more time resting, which can significantly impact their survival and geographic distribution. Our previous work on long-tailed macaques demonstrated that individuals who monitored more frequently humans spent less time grooming, although there was no association between macaque's monitoring and any specific type of human-macaque interaction (Marty et al., 2019).

Interestingly, some urban-dwelling populations have been shown to spend more time resting and engaging in social activities compared to less urban groups (Saj et al., 1999; El Alami et al., 2012; Jaman \& Huffman, 2013; Ilham et al., 2018; Koirala et al., 2017; Thatcher et al., 2019). This suggests a potentially positive effect (rather than negative) of anthropogenic factors on animals' time budgets. We argue that the difference between the results found in our study, which support the time constraints hypothesis, and those reported in previous studies, which are consistent with the free time hypothesis, might be due to the degree of predictability that different animal populations might face in accessing human food or avoiding human aggression. In other words, our study populations experienced an almost equal amount of positive (human provision) and negative (human aggression) interactions with people, making human behavior highly unpredictable for the macaques. This pattern of interactions contrasts with what has been reported in some other urban-dwelling species, where either a single type of interaction is more common (e.g., human provisoning tends to occur more frequently than human aggression: Saj, 1998; Hsu et al., 2008) or direct human-macaque interactions are infrequent (e.g., Jaman \& Huffman, 2013). Therefore, macaques in Jakhoo might need to spend a substantial amount of time monitoring human activity in order to better understand people's intentions. This can explain why we found that monitoring time was positively predicted by the rates of all human-macaque interactions, and the latter had a negative impact on both macaque resting and grooming time. Given the importance of social grooming for animal's fitness and for group cohesion, this may have significant long-term 

al., 2009).

In addition to the degree of (un)predictability of human behavior, it is possible that the nutritional content of human food consumed might also drive the high levels of macaques' monitoring of human activity observed in our site. Although our work does not include nutritional analyses, we frequently observed people providing macaques with sugar pellets. Previous laboratory work has shown that intermittent access to food with high sugar content leads individuals to crave more of that high-sugar food (Hoebel et al., 2009). This potential addiction to human food in Jakhoo might be one of the reasons macaques in our study groups frequently initiated interactions with people. Future nutritional analyses on the macaques in our study site are needed in order to carefully examine the nutritional content of anthropogenic and natural food they consume and how this may, in turn, drive human-macaque interactions. Understanding the nutritional and energetic content of human foods compared to natural food in our study site could also shed light on the economic trade-offs that macaques experience between the benefits of accessing human food, and the costs of reducing their resting and social time.

The long-term effects of a reduction in resting and social time in our study population are still unclear. Dunbar and colleagues (Dunbar, 1996; Dunbar et al., 2009; Korstjens et al., 2010) suggested that animals can engage in two different types of resting. One form of resting (named enforced resting time) is the time animals use for digestion or for thermoregulation, while a different type of resting, named free resting time, is the time that is genuinely free and that can be used for other activities. Enforced resting time is likely to be particularly important for folivorous species (given the substantial amount of time needed for fermentation) and for animals that live at extreme temperatures (Dunbar et al., 2009; Korstjens et al., 2010). While our data do not allow us to differentiate between enforced and free resting time, we suggest that the enforced resting time in our study populations might be minimal. 
Rhesus macaques are a generalist species with a flexible diet (Fooden, 2000; Southwick \& Siddiqi, 2011) so their diet is not restricted solely to leaves. Furthermore, annual temperatures in Shimla range from $4^{\circ} \mathrm{C}$ to $+31^{\circ} \mathrm{C}$ with an average of $18^{\circ} \mathrm{C}$ (www.weather-and-climate.com) and are therefore temperate enough that it is unlikely that the macaques need a high amount of enforced resting time for thermoregulation. We therefore suggest that the majority of this resting time is actually free time macaques have available to engage in other activities, which might explain why macaques in our study population are willing to forgo resting in order to interact with people to receive food from them.

Our analysis of grooming time showed that even though both sexes reduced their grooming time in response to increased interactions with people, females maintained higher overall levels of grooming than males. This is consistent with Dunbar \& Dunbar (1988)'s hypothesis that, given the importance of social interactions for group cohesion and individuals' fitness, when animals face time constraints they first tend to draw on resting time, while maintaining social time. Among macaques, females are the philopatric sex, and form the core of the social group (Pusey \& Packer, 1987). Social grooming is more frequently exchanged among close-kin females within stable matrilines (Kapsalis, 2004) but may also occur among non-kin across matrilines (Clutton-Brock, 2002). Thus, female-female grooming among macaques is key for the maintenance of group social stability and cohesion (Cords, 2012), which can explain why females engaged in higher rates of grooming interactions than males despite the humaninduced time constraints on this social behavior. Indeed, previous work on captive rhesus macaques has shown that a low genetic relatedness might result in more fragmentation and/or sub-grouping in grooming networks, which can result in higher social instability and wounding (Beisner et al., 2011; McCowan et al., 2018). Interestingly high-ranking females seemed to experience more time constraints on social grooming than subordinate females. Work across a variety of primate species has shown that social grooming may be used by subordinates as a way to obtain rank-restricted services in return, such as agonistic support (Hemelrijk, 1994; Schino et al., 2007; Carne et al., 2011; Kaburu \& Newton-Fisher, 
2015), tolerance in feeding contexts (Carne et al., 2011; Tiddi et al., 2011; Balasubramaniam \& Berman, 2017) and reduction of aggression (Ventura et al., 2006; Gumert \& Ho, 2008; Xia et al., 2012; Xia et al., 8

\section{Acknowledgments}

This work was supported by the National Science Foundation Grant\#1518555 to Brenda McCowan. We thank the Himachal Pradesh Forest Department for giving us permission to conduct our research in Shimla. We are also grateful to Eduardo Saczek, Taniya Gill, Kawaljit Kaur, Bidisha Chakraborty, 
Benjamin Sipes and Nalina Aiempichitkijkarn for their assistance with data collection, and to Santosh

Thakur for assisting with the logistics during field work. Finally, we would like to extend our gratitude to two anonymous reviewers for providing constructive comments on a previous draft of the manuscript.

\section{References}

Altmann, J. (1974). Observational study of behavior: sampling methods.- Behaviour 49:227-266.

Aublet, J-F., Festa-Bianchet, M., Bergero, D. \& Bassano, B. (2009). Temperature constraints on foraging behaviour of male Alpine ibex (Capra ibex) in summer.- Oecologia 159:237-247.

Backwell, P.R. \& Passmore, N.I. (1996). Time constraints and multiple choice criteria in the sampling behaviour and mate choice of the fiddler crab, Uca annulipes.- Behav. Ecol. Sociobiol. 38:407416.

Balasubramaniam, K. N., \& Berman, C. M. (2017). Grooming interchange for resource tolerance: biological markets principles within a group of free-ranging rhesus macaques.- Behaviour, 154: 1145-1176.

Barua, M., Bhagwat, S.A. \& Jadhav, S. (2013). The hidden dimensions of human-wildlife conflict: health impacts, opportunity and transaction costs.- Biol. Conserv. 157:309-316.

Beisner, B.A., Heagerty, A., Seil, S.K., Balasubramaniam, K.N., Atwill, E.R., Gupta, B.K., Tyagi, P.C., Chauhan, N.P., Bonal, B., Sinha, P. \& McCowan, B. (2015). Human-wildlife conflict: proximate predictors of aggression between humans and rhesus macaques in India.- Am. J. Physic. Anthropol. 156:286-294.

Beisner, B.A., Jackson, M.E., Cameron, A.N. \& McCowan, B. (2011). Detecting instability in animal social networks: genetic fragmentation is associated with social instability in rhesus macaques.PloS One 6:e16365. 
Black, J.M., Carbone, C., Wells, R. \& Owen, M. (1992). Foraging dynamics in goose flocks: the cost of living on the edge.- Anim. Behav. 44:41-50.

Brotcorne, F., Giraud, G., Gunst, N., Fuentes, A., Wandia, I.N., Beudels-Jamar, R.C., Poncin, P., Huynen, M-C. \& Leca, J-B. (2017). Intergroup variation in robbing and bartering by long-tailed macaques at Uluwatu Temple (Bali, Indonesia).- Primates 58:1-12.

Burnham, K.P., Anderson, D.R. \& Huyvaert, K.P. (2011). AIC model selection and multimodel inference in behavioral ecology: some background, observations, and comparisons.- Behav. Ecol. Sociobiol. 65:23-35.

Carne, C., Wiper, S. \& Semple, S. (2011). Reciprocation and interchange of grooming, agonistic support, feeding tolerance, and aggression in semi-free-ranging Barbary macaques.- Am. J. Primatol. 73:1127-1133.

Chapman, C.A., Chapman, L.J. \& Wrangham, R. (1995). Ecological constraints on group size: an analysis of spider monkey and chimpanzee subgroups.- Behav. Ecol. Sociobiol. 36:59-70.

Chauhan, A. \& Pirta, R. (2010a). Agonistic interactions between humans and two species of monkeys (rhesus monkey Macaca mulatta and hanuman langur Semnopithecus entellus) in Shimla, Himachal Pradesh.- J. Psychol. 1:9-14.

Chauhan, A. \& Pirta, R. (2010b). Socio-ecology of two species of non-human primates, rhesus monkey (Macaca mulatta) and Hanuman langur (Semnopithecus entellus), in Shimla, Himachal Pradesh.J. Hum. Ecol. 30:171-177.

Clutton-Brock, T. (2002). Breeding together: kin selection and mutualism in cooperative vertebrates.Science 296:69-72.

Cords, M. (2012). The behavior, ecology, and social evolution of cercopithecine monkeys.- In: The evolution of primate societies (Mitani, J.C, Call, J., Kappeler, P.M., Ryne, A.P., Silk, J.B., eds.). University of Chicago Press, Chicago, p. 91-112. 
Dickman, A.J. (2012). From cheetahs to chimpanzees: a comparative review of the drivers of humancarnivore conflict and human-primate conflict.- Folia Primatol. 83:377-387.

8

Duchesne, M., Côté, S.D. \& Barrette, C. (2000). Responses of woodland caribou to winter ecotourism in the Charlevoix Biosphere Reserve, Canada.- Biol. Conserv. 96:311-317.

Dunbar, R.I.M. (1996). Determinants of group size in primates: a general model.- Proc. Br. Acad. 88: 33-57.

Dunbar, R.I.M. \& Dunbar, P. (1988). Maternal time budgets of gelada baboons.- Anim. Behav. 36:970980.

Dunbar, R.I.M., Hannah-Stewart, L. \& Dunbar, P. (2002). Forage quality and the costs of lactation for female gelada baboons.- Anim. Behav. 64:801-805.

Dunbar, R.I.M. (1988). Primate social systems.- Cornell University Press, Ithaca, NY.

Dunbar, R.I.M. (1991). Functional significance of social grooming in primates.- Folia Primatol. 57:121131.

Dunbar, R.I.M. (1992). Time: a hidden constraint on the behavioural ecology of baboons. .- Behav. Ecol. Sociobiol. 31:35-49.

Dunbar, R.I.M. (2010). The social role of touch in humans and primates: behavioural function and neurobiological mechanisms.- Neurosci. Biobehav. Rev. 34:260-268.

Dunbar, R.I.M., Korstjens, A.H. \& Lehmann, J. (2009). Time as an ecological constraint.- Biol. Rev. 84:413-429.

Dunbar, R.I.M. \& Shi, J. (2013). Time as a constraint on the distribution of feral goats at high latitudes.Oikos 122:403-410.

El Alami, A., Van Lavieren, E., Rachida, A. \& Chait, A. (2012). Differences in activity budgets and diet between semiprovisioned and wild- feeding groups of the endangered Barbary Macaque 
(Macaca sylvanus) in the Central High Atlas Mountains, Morocco.- Am. J. Primatol. 74:210216.

Fooden, J. (2000). Systematic review of rhesus macaque, Macaca mulatta (Zimmermann, 1780).Fieldiana Zool. 96:1-180.

Formica, V.A., Wood, C., Larsen, W., Butterfield, R., Augat, M., Hougen, H. \& Brodie III, E. (2012). Fitness consequences of social network position in a wild population of forked fungus beetles (Bolitotherus cornutus)-- J. Evol. Biol. 25:130-137.

Forthman-Quick, D. (1988). Dynamics of exploitation: differential energetic adaptations of two troops of baboons to recent human contact.- In: Ecology and behavior of food enhanced primate groups (Fa, J.E. \& Southwick, C.H. eds.). Liss, New York, p. 25-51.

Frère, C.H., Krützen, M., Mann, J., Connor, R.C., Bejder, L. \& Sherwin, W.B. (2010). Social and genetic interactions drive fitness variation in a free-living dolphin population.- Proc. Natl. Acad. Sci. 107:19949-19954.

Fuentes, A. (2012). Ethnoprimatology and the anthropology of the human-primate interface--Annu. Rev. Anthropol. 41:101-117.

Fujii, K., Jin, J., Shev, A., Beisner, B., McCowan, B. \& Fushing, H. (2015). Perc: using percolation and conductance to find information flow certainty in a direct network. R Package Version 0.1.

Fushing, H., McAssey, M.P., Beisner, B. \& McCowan B. (2011). Ranking network of a captive rhesus macaque society: a sophisticated corporative kingdom.- Plos One 6:e17817.

Gelman, A. (2008). Scaling regression inputs by dividing by two standard deviations.- Stat Med 27: 2865-2873.

Grover, K.E. \& Thompson, M.J. (1986). Factors influencing spring feeding site selection by elk in the Elkhorn Mountains, Montana. - J. Wildl. Manage. 50:466-470. 
Gumert, M.D. \& Ho, M-HR (2008). The trade balance of grooming and its coordination of reciprocation and tolerance in Indonesian long-tailed macaques (Macaca fascicularis). - Primates 49:176 - 185

Hemelrijk, C.K. (1994). Support for being groomed in long-tailed macaques, Macaca fascicularis. Anim. Behav. 48:479-481.

Henzi, S.P. \& Barrett, L. (1999). The value of grooming to female primates.- Primates 40:47-59.

Herbers, J.M. (1981). Time resources and laziness in animals.- Oecologia 49:252-262.

Hockings, K.J., Anderson, J.R. \& Matsuzawa, T. (2012). Socioecological adaptations by chimpanzees, Pan troglodytes verus, inhabiting an anthropogenically impacted habitat-- Anim. Behav. 83:801810.

Hodgson, A. J., Marsh, H., \& Corkeron, P. J. (2004). Provisioning by tourists affects the behaviour but not the body condition of Mareeba rock-wallabies (Petrogale mareeba) .- Wildlife Res. 31(4): 451-456.

Hoebel, B.G., Avena, N.M., Bocarsly, M.E. \& Rada, P. (2009). A behavioral and circuit model based on sugar addiction in rats. - J. Addict. Med. 3:33-41.

Hsu, M.J., Kao, C. \& Agoramoorthy, G. (2008). Interactions between visitors and Formosan macaques (Macaca cyclopis) at Shou- Shan Nature Park, Taiwan. - Am. J. Primatol 71: 214-222.

Ilham, K., Nurdin, J. \& Tsuji, Y. (2018). Effect of provisioning on the temporal variation in the activity budget of urban long-tailed macaques (Macaca fascicularis) in West Sumatra, Indonesia. - Folia Primatol. 89:347-356.

Jaman, M.F. \& Huffman, M.A. (2013). The effect of urban and rural habitats and resource type on activity budgets of commensal rhesus macaques (Macaca mulatta) in Bangladesh.- Primates 54:49-59.

Johansson, F. \& Rowe, L. (1999). Life history and behavioral responses to time constraints in a damselfly.- Ecology 80:1242-1252. 
Johansson, F., Stoks, R., Rowe, L. \& De Block, M. (2001). Life history plasticity in a damselfly: effects of combined time and biotic constraints.- Ecology 82:1857-1869.

8

Kaburu, S.S.K. \& Newton-Fisher, N.E. (2015). Egalitarian despots: hierarchy steepness, reciprocity and the grooming-trade model in wild chimpanzees, Pan troglodytes. - Anim. Behav. 99:61-71.

Kaburu, S.S.K., Marty, P., Beisner, B., Balasubramanian, K., Bliss-Moreau, E., Kawaljit, K., Mohan, L. \& McCowan, B. (2019). Rates of human-macaque interactions affect grooming behavior among urban-dwelling rhesus macaques (Macaca mulatta). - Am. J Physic. Anthropol. 168:92-103.

Kappeler, P. M., Cremer, S., \& Nunn, C. L. (2015). Sociality and health: impacts of sociality on disease susceptibility and transmission in animal and human societies. -Philos. Trans. R. Soc. Lond., B, Biol. Sci. 370: 20140116.

Kapsalis, E. (2004). Matrilineal kinship and primate behavior. - In: Kinship and behavior in primates (Chapais, B. \& Berman, C. eds.). - Oxford University Press, Oxford, UK, p. 153-176.

Keys, G.C. \& Dugatkin, L.A. (1990). Flock size and position effects on vigilance, aggression, and prey capture in the European starling. - Condor 92:151-159.

Koirala, S., Chalise, M.K., Katuwal, H.B., Gaire, R., Pandey, B. \& Ogawa, H. (2017). Diet and activity of Macaca assamensis in wild and semi-provisioned groups in Shivapuri Nagarjun National Park, Nepal. - Folia Primatol. 88:57-74.

Korstjens, A.H., Lehmann, J. \& Dunbar, R.I.M. (2010). Resting time as an ecological constraint on primate biogeography.- Anim. Behav. 79:361-374.

Korstjens, A.H., Lehmann, J. \& Dunbar, R.I.M. (2018). Time constraints do not limit group size in arboreal guenons but do explain community size and distribution patterns.- Int. J. Primatol. 39:511-531.

Korstjens, A.H., Verhoeckx, I.L. \& Dunbar, R.I.M. (2006). Time as a constraint on group size in spider monkeys.- Behav. Ecol. Sociobiol. 60:683-694. 
Lehmann, J., Korstjens, A.H. \& Dunbar, R.I.M. (2010). Apes in a changing world-the effects of global warming on the behaviour and distribution of African apes. - J. Biogeogr. 37:2217-2231.

Lewis, S., Schreiber, E.A., Daunt, F., Schenk, G., Wanless, S. \& Hamer, K. (2004). Flexible foraging patterns under different time constraints in tropical boobies. Anim. Behav. 68:1331-1337.

Lipetz, V.E. \& Bekoff, M. (1982). Group size and vigilance in pronghorns. - Z. Tierpsychol. 58:203216.

Lott, D.F. \& McCoy, M. (1995). Asian rhinos Rhinoceros unicornis on the run? Impact of tourist visits on one population. Biol. Conserv.73:23-26.

Majolo, B., van Lavieren, E., Maréchal, L., MacLarnon, A., Marvin, G., Qarro, M, \& Semple, S. (2013). Out of Asia: The singular case of the Barbary macaque. In The Macaque Connection (Radhakrishna, S., Huffman, M.A., Sinha, A. eds.).- Springer, New York, p. 167-183.

Maréchal, L., MacLarnon, A., Majolo, B., \& Semple, S. (2016). Primates' behavioural responses to tourists: evidence for a trade-off between potential risks and benefits. Sc. Report, 6.

Marty, P., Beisner, B., Kaburu, S.S.K., Balasubramaniam, K., Bliss-Moreau, E., Ruppert, N., Sah, S., Ahmad, I., Arlet, M., Atwill, E. \& McCowan, B, 2019. Time constraints and stress imposed by human presence alter social behaviour in urban long-tailed macaques. -Anim. Behav. 150: 157165.

McCarthy, M. S., Matheson, M. D., Lester, J. D., Sheeran, L. K., Li, J. H., \& Wagner, R. S. (2009). Sequences of Tibetan macaque (Macaca thibetana) and tourist behaviors at Mt. Huangshan, China. - Primate Conserv. 24(1): 145-152.

McCowan, B., Beisner, B., \& Hannibal, D. (2018). Social management of laboratory rhesus macaques housed in large groups using a network approach: A review. - Behav Processes 156: 77-82.

McFarland, R., Barrett, L., Boner, R., Freeman, N.J. \& Henzi, S.P (2014). Behavioral flexibility of vervet monkeys in response to climatic and social variability. - Am. J. Physic. Anthropol. 154:357-364. 
McLennan, M.R. \& Ganzhorn, J.U. (2017). Nutritional characteristics of wild and cultivated foods for chimpanzees (Pan troglodytes) in agricultural landscapes. - Int. J. Primatol. 38:122-150.

Menon, S. \& Poirier, F.E. (1996). Lion-tailed macaques (Macaca silenus) in a disturbed forest fragment: activity patterns and time budget. - Int. J. Primatol. 17:969-985.

Murton, R., Isaacson, A. \& Westwood, N. (1971). The significance of gregarious feeding behaviour and adrenal stress in a population of Wood- pigeons Columba palumbus.- J. Zool. 165:53-84.

Nyhus, P.J. (2016). Human-wildlife conflict and coexistence. Annu. Rev. Environ. Resour. 41:143-171.

Owen-Smith, N. (1998). How high ambient temperature affects the daily activity and foraging time of a subtropical ungulate, the greater kudu (Tragelaphus strepsiceros). - J. Zool. 246:183-192.

Petit, D.R. \& Bildstein, K.L. (1987). Effect of group size and location within the group on the foraging behavior of white ibises. - Condor 89:602-609.

Pollard, K.A. \& Blumstein, D.T. (2008). Time allocation and the evolution of group size.- Anim. Behav. 76:1683-1699.

Priston, N.E. \& McLennan, M.R. (2013). Managing humans, managing macaques: human-macaque conflict in Asia and Africa. - In: The macaque connection: cooperation and conflict between humans and macaques (Radhakrishna, S., Huffman, M.A. \& Sinha, A. eds.). - Springer, New York, p. 225-250.

Pusey, A. \& Packer, C. (1987). Dispersal and philopatry. - In: Primate Societies (Smuts, B.B., Cheney, D.L., Seyfarth, R.M., Wrangham, R.W. \& Struhsaker, T.T. eds.). - Chicago University Press, Chicago, p. 250-266.

Rhine, R. J., Cox, R. L., \& Costello, M. B. (1989). A twenty-year study of long-term and temporary dominance relations among stumptailed macaques (Macaca arctoides).- Am. J. Primatol. 19(2): 69-82. 
Richards, S.A., Whittingham, M.J. \& Stephens, P.A. (2011). Model selection and model averaging in behavioural ecology: the utility of the IT-AIC framework. - Behav. Ecol. Sociobiol. 65:77-89.

Riley, E.P. (2007). Flexibility in diet and activity patterns of Macaca tonkeana in response to anthropogenic habitat alteration. - Int. J. Primatol. 28:107-133.

Riley, E.P., Tolbert, B. \& Farida, W.R. (2013). Nutritional content explains the attractiveness of cacao to crop raiding Tonkean macaques.- Curr. Zool. 59:160-169.

Rode, K.D., Chiyo, P.I., Chapman, C.A. \& McDowell, L.R. (2006). Nutritional ecology of elephants in Kibale National Park, Uganda, and its relationship with crop-raiding behaviour. - J. Trop. Ecol. 22:441-449.

Roser, M. \& Ortiz-Ospina, Es. (2018). World Population Growth. OurWorldInDataorg.

Saj, T. L. (1998). The ecology and behavior of vervet monkeys in a human-modified environment. MA thesis, University of Calgary.

Saj, T.L., Sicotte, P. \& Paterson, J.D. (1999). Influence of human food consumption on the time budget of vervets. - Int. J. Primatol. 20: 977-994.

Schino, G., di Sorrentino, E.P. \& Tiddi, B. (2007). Grooming and coalitions in Japanese macaques (Macaca fuscata): partner choice and the time frame reciprocation. - J. Comp. Psychol. 121:181.

Siikamäki, P. (1998). Limitation of reproductive success by food availability and breeding time in pied flycatchers.- Ecology 79:1789-1796.

Silk, J.B., Alberts, S.C. \& Altmann, J. (2003). Social bonds of female baboons enhance infant survival. Science 302:1231-1234.

Snyder-Mackler, N., Kohn, J.N., Barreiro, L.B., Johnson, Z.P., Wilson, M.E. \& Tung, J. ( 2016). Social status drives social relationships in groups of unrelated female rhesus macaques. - Anim. Behav. 111:307-317. 
Southwick, C.H. \& Siddiqi, F. (2011). India's rhesus population: Protection versus conservation management. - In: Monkeys on the edge: Ecology and management of Long-tailed macaques and their interface with humans (Gumert, D., Fuentes, A. \& Jones-Engel, L. eds.). Cambridge University Press, Cambridge, p. 275-292.

Sueur, C., Petit, O., De Marco, A., Jacobs, A.T., Watanabe, K. \& Thierry, B. (2011). A comparative network analysis of social style in macaques. - Anim. Behav. 82:845-852.

Szott, I. D., Pretorius, Y., \& Koyama, N. F. (in press). Behavioural changes in African elephants in response to wildlife tourism.- J Zool.

Thatcher, H.R., Downs, C.T. \& Koyama, N.F. (2019). Anthropogenic influences on the time budgets of urban vervet monkeys. - Landsc Urban Plan 181:38-44.

Tiddi, B., Aureli, F., Polizzi di Sorrentino, E., Janson, C.H. \& Schino, G. (2011). Grooming for tolerance? Two mechanisms of exchange in wild tufted capuchin monkeys. - Behav. Ecol. 22:663-669.

Ventura, R., Majolo, B., Koyama, N.F., Hardie, S. \& Schino, G. (2006). Reciprocation and interchange in wild Japanese macaques: grooming, cofeeding, and agonistic support. - Am. J. Primatol. 68:1138-1149.

Vitousek, P.M., Mooney, H.A., Lubchenco, J. \& Melillo, J.M. (1997). Human domination of Earth's ecosystems. - Science 277:494-499.

Xia, D.P., Li, J., Garber, P.A., Sun, L., Zhu, Y. \& Sun, B. (2012). Grooming reciprocity in female Tibetan macaques Macaca thibetana. - Am. J. Primatol. 74:569-579.

Xia, D.P., Li, J.H., Garber, P.A., Matheson, M.D., Sun, B.H. \& Zhu, Y. (2013). Grooming reciprocity in male Tibetan macaques. - Am. J. Primatol. 75:1009-1020.

Young, C., Majolo, B., Heistermann, M., Schülke, O. \& Ostner, J. (2014). Responses to social and environmental stress are attenuated by strong male bonds in wild macaques. - Proc. Natl. Acad. Sci. U. S. A. 111 (51): 18195-18200. 
Table 1. Summary of the outcome variables and predictors included in the GLMM models. All models included group membership as random factor and total number of scans as exposure variable.

\begin{tabular}{|c|c|c|}
\hline Prediction & Outcome & Predictors \\
\hline $1 \mathrm{a}$ & Monitoring & $\begin{array}{l}\text {-All human-macaque interactions } \\
\text {-Human provisioning macaques } \\
\text {-Macaque submission } \\
\text {-Macaque-to-human non-aggressive behaviors } \\
\text {-Human aggression } \\
\text {-Sex } \\
\text {-Rank }\end{array}$ \\
\hline $\begin{array}{l}1 \mathrm{~b} \\
1 \mathrm{c}\end{array}$ & $\begin{array}{l}\text { Resting } \\
\text { Grooming }\end{array}$ & $\begin{array}{l}\text {-All human-macaque interactions } \\
\text {-Macaque submission } \\
\text {-Macaque-to-human non-aggressive behaviors } \\
\text {-Macaque aggression } \\
\text {-Monitoring* } \\
\text {-Sex } \\
\text {-Rank }\end{array}$ \\
\hline $\begin{array}{l}2 \mathrm{a} \\
2 \mathrm{~b}\end{array}$ & $\begin{array}{l}\text { Resting } \\
\text { Grooming }\end{array}$ & $\begin{array}{l}\text {-Foraging on } \\
\text { anthropogenic food } \\
\text {-Sex } \\
\text {-Rank }\end{array}$ \\
\hline
\end{tabular}

*Monitoring was not included in the model where resting was the outcome variable. 
Table 2. Summary of the rates of human-macaque interactions and macaques' activities. Rates of human-macaque interactions are expressed as number of events per hour of observation. Rates of macaques' monitoring, resting and grooming are expressed as number of scans in which the focal animal was observed monitoring, resting or grooming, respectively, divided by the total number of scans. Rates of macaques' foraging on anthropogenic food are expressed as number of scans the focal animal was observed foraging on anthropogenic food divided by the total number of times the animal was scored foraging.

\begin{tabular}{llll}
\hline \multicolumn{1}{c}{ Behavior } & Mean $( \pm$ SE) & Median & Range \\
\hline All human-macaque interactions & $2.61( \pm 1.19)$ & 2.43 & $0.18-5.96$ \\
Human provisioning macaques & $0.51( \pm 0.42)$ & 0.42 & $0.00-1.90$ \\
Human aggression & $0.64( \pm 0.41)$ & 0.59 & $0.00-2.13$ \\
Macaque avoidance of humans & $0.88( \pm 0.41)$ & 0.84 & $0.00-2.14$ \\
Macaque non-aggressive behaviors & $0.28( \pm 0.41)$ & 0.10 & $0.00-2.31$ \\
Monitoring & $0.08( \pm 0.04)$ & 0.07 & $0.02-0.21$ \\
Resting & $0.39( \pm 0.08)$ & 0.38 & $0.19-0.67$ \\
Grooming & $0.18( \pm 0.07)$ & 0.17 & $0.02-0.36$ \\
Foraging on anthropogenic food & $0.39( \pm 0.19)$ & 0.39 & $0-00-1.00$ \\
\hline
\end{tabular}


Table 3. Results of the best-fit negative binomial GLMM testing the effect of humanmacaque interactions, rank and sex on monitoring time. Significant predictors are indicated in bold.

\begin{tabular}{cccccc}
\hline Outcome & Predictors & Estimate & SE & z-value & p-value \\
\hline Monitoring & Intercept & -2.67 & 0.09 & -28.51 & $<0.001$ \\
& Rank & -0.03 & 0.04 & -0.71 & 0.475 \\
& Sex & 0.13 & 0.09 & 1.47 & 0.142 \\
& All human-macaque interactions & $\mathbf{0 . 2 8}$ & $\mathbf{0 . 0 4}$ & $\mathbf{6 . 6 5}$ & $<\mathbf{0 . 0 0 1}$ \\
& All human-macaque interactions & $\mathbf{- 0 . 1 2}$ & $\mathbf{0 . 0 6}$ & $\mathbf{- 2 . 1 9}$ & $\mathbf{0 . 0 2 8}$ \\
\hline Monitoring & Sex & -2.66 & 0.09 & -28.46 & $<0.001$ \\
& Intercept & 0.11 & 0.09 & 1.24 & 0.216 \\
& Rank & -0.02 & 0.04 & -0.51 & 0.608 \\
& Sex & $\mathbf{0 . 2 3}$ & $\mathbf{0 . 0 3}$ & $\mathbf{7 . 2 7}$ & $<\mathbf{0 . 0 0 1}$ \\
& All human-macaque interactions & & & 0.071 \\
& All human-macaque interactions & -0.05 & 0.03 & -1.81 & \\
& $*$ Rank & & & & \\
\hline
\end{tabular}


Table 4. Results of the best-fit negative binomial GLMM testing the effect of humanmacaque interactions, rank and sex on resting time. Significant predictors are indicated in bold.

\begin{tabular}{cccccc}
\hline Outcome & Predictors & Estimate & SE & z-value & p-value \\
\hline Resting & Intercept & -1.03 & 0.02 & -50.32 & $<0.001$ \\
& Rank & -0.03 & 0.02 & -1.46 & 0.143 \\
& Sex & $\mathbf{0 . 2 6}$ & $\mathbf{0 . 0 5}$ & $\mathbf{5 . 6 1}$ & $<\mathbf{0 . 0 0 1}$ \\
& All human-macaque interactions & $\mathbf{- 0 . 0 5}$ & $\mathbf{0 . 0 2}$ & $\mathbf{- 3 . 2 5}$ & $\mathbf{0 . 0 0 1}$ \\
& Human-macaque interactions & 0.03 & 0.02 & 1.64 & 0.101 \\
\hline Resting & Rank & -1.03 & 0.02 & -49.41 & $<0.001$ \\
& Intercept & -0.03 & 0.02 & -1.46 & 0.145 \\
& Rank & $\mathbf{0 . 2 6}$ & $\mathbf{0 . 0 5}$ & $\mathbf{5 . 5 0}$ & $<\mathbf{0 . 0 0 1}$ \\
& Sex & $\mathbf{- 0 . 0 5}$ & $\mathbf{0 . 0 2}$ & $\mathbf{- 2 . 8 1}$ & $\mathbf{0 . 0 0 5}$ \\
\hline
\end{tabular}


Table 5. Results of the best-fit negative binomial GLMM testing the effect of monitoring, human-macaque interactions, rank and sex on grooming time. Significant predictors are indicated in bold.

\begin{tabular}{cccccc}
\hline Outcome & Predictors & Estimate & SE & z-value & p-value \\
\hline Grooming & Intercept & -1.50 & 0.10 & -15.55 & $<0.001$ \\
& Rank & $\mathbf{0 . 1 2}$ & $\mathbf{0 . 0 4}$ & $\mathbf{2 . 7 4}$ & $\mathbf{0 . 0 0 6}$ \\
& Sex & -1.13 & $\mathbf{0 . 1 6}$ & $\mathbf{- 7 . 2 6}$ & $<\mathbf{0 . 0 0 1}$ \\
& All human-macaque interactions & 0.003 & 0.05 & 0.01 & 0.994 \\
Rank * Sex & $\mathbf{0 . 4 2}$ & $\mathbf{0 . 1 3}$ & $\mathbf{3 . 2 5}$ & $\mathbf{0 . 0 0 1}$ \\
& All human-macaque interactions * Rank & -0.07 & 0.05 & -1.35 & 0.177 \\
& All human-macaque interactions * Sex & $\mathbf{- 0 . 3 0}$ & $\mathbf{0 . 1 0}$ & $\mathbf{- 3 . 0 8}$ & $\mathbf{0 . 0 0 2}$ \\
& All human-macaque interactions * Rank * Sex & $\mathbf{0 . 2 2}$ & $\mathbf{0 . 0 9}$ & $\mathbf{2 . 3 5}$ & $\mathbf{0 . 0 1 8}$ \\
\hline
\end{tabular}


Table 6. Results of the best-fit negative binomial GLMM testing the effect of foraging on anthropogenic food, rank and sex on resting and grooming time. Significant predictors are indicated in bold.

\begin{tabular}{cccccc}
\hline Outcome & Predictor & Estimate & SE & z-value & p-value \\
\hline Resting & Intercept & -1.03 & 0.02 & -48.61 & $<0.001$ \\
& Rank & -0.03 & 0.02 & -1.48 & 0.139 \\
& Sex & $\mathbf{0 . 2 8}$ & $\mathbf{0 . 0 5}$ & $\mathbf{5 . 7 7}$ & $<\mathbf{0 . 0 0 1}$ \\
& Foraging on anthropogenic food & -0.03 & 0.02 & -1.95 & 0.051 \\
\hline Grooming & Intercept & -1.49 & 0.10 & -14.69 & $<0.001$ \\
& Rank & $\mathbf{0 . 1 5}$ & $\mathbf{0 . 0 4}$ & $\mathbf{3 . 4 5}$ & $<\mathbf{0 . 0 0 1}$ \\
& Sex & $\mathbf{- 0 . 7 0}$ & $\mathbf{0 . 1 0}$ & $\mathbf{- 7 . 0 3}$ & $<\mathbf{0 . 0 0 1}$ \\
\hline
\end{tabular}



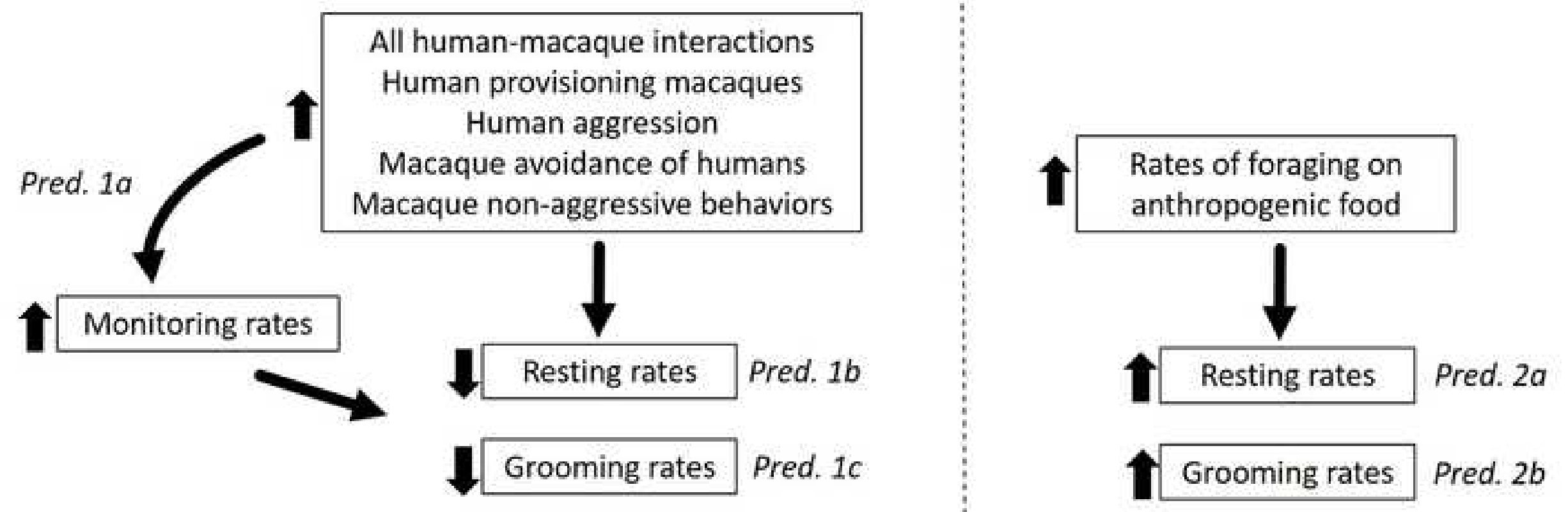

Time constraints hypothesis

Free time hypothesis

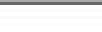

pred. 2 
Figure 2

Click here to access/download;Figure;Figure 2.jpg $\underline{\underline{ }}$

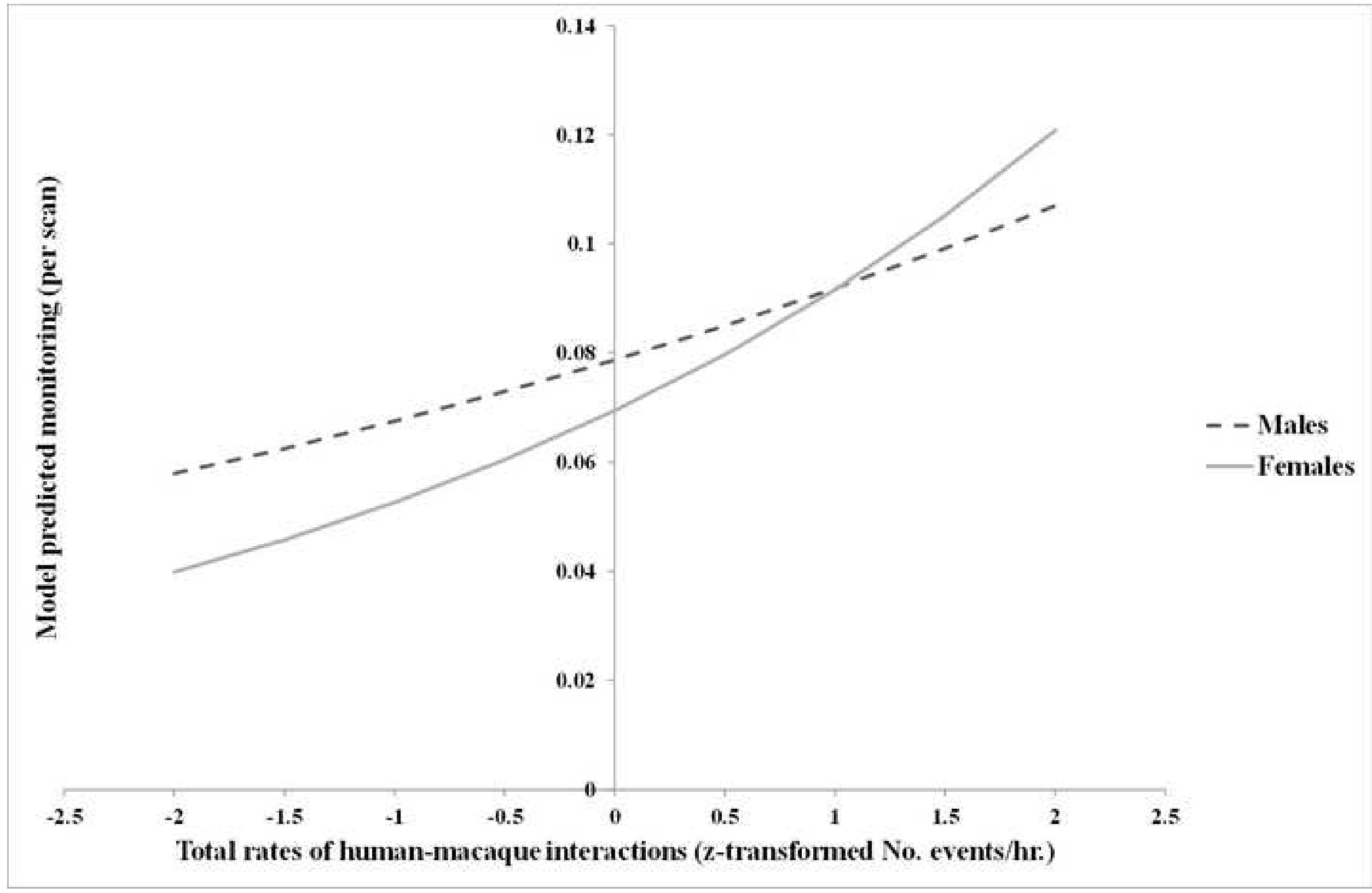




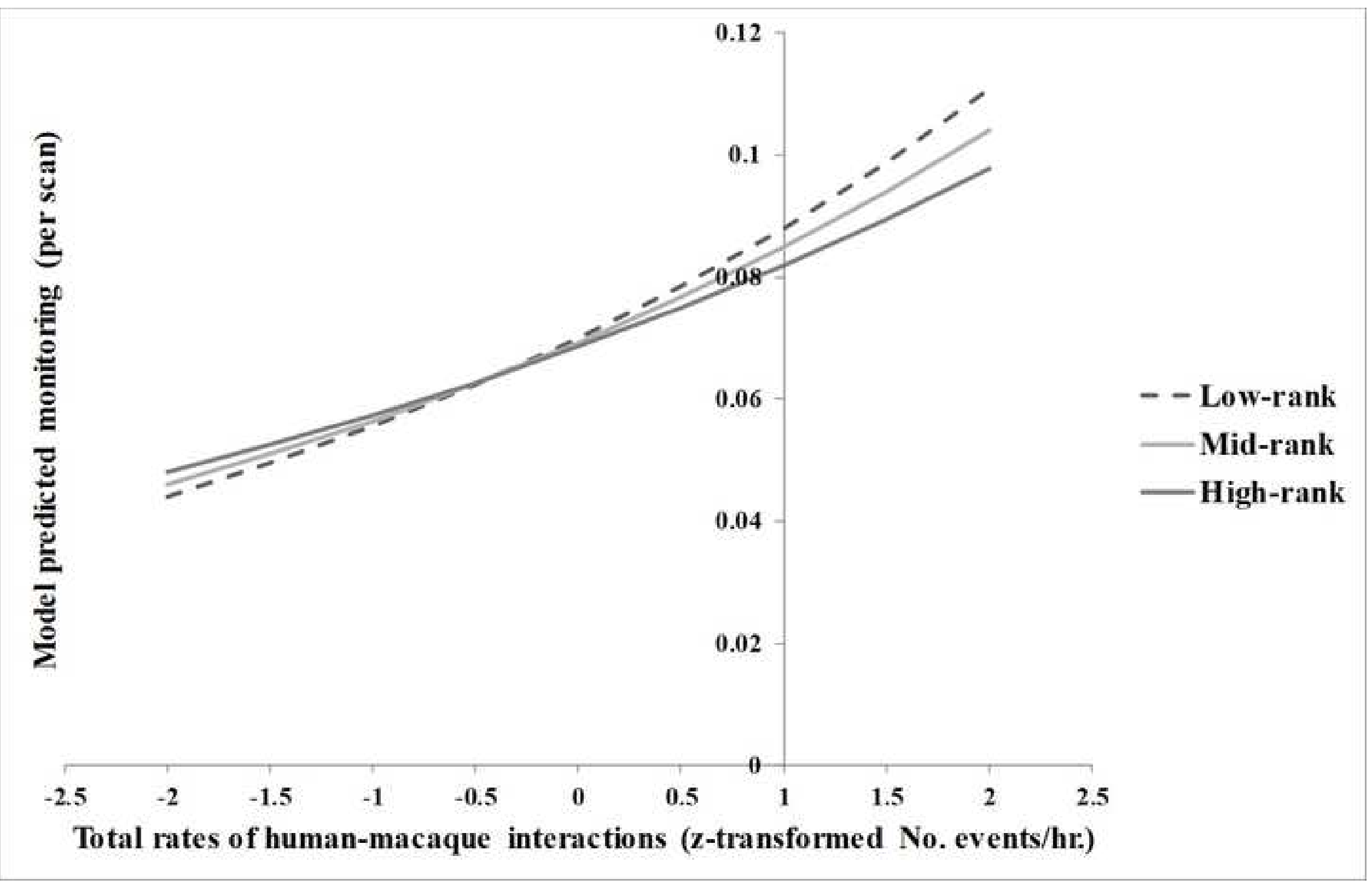

- Low-rank High-rank

$$
\text { Total rates of human-macaque interactions (z-transformed No. events/hr) }
$$




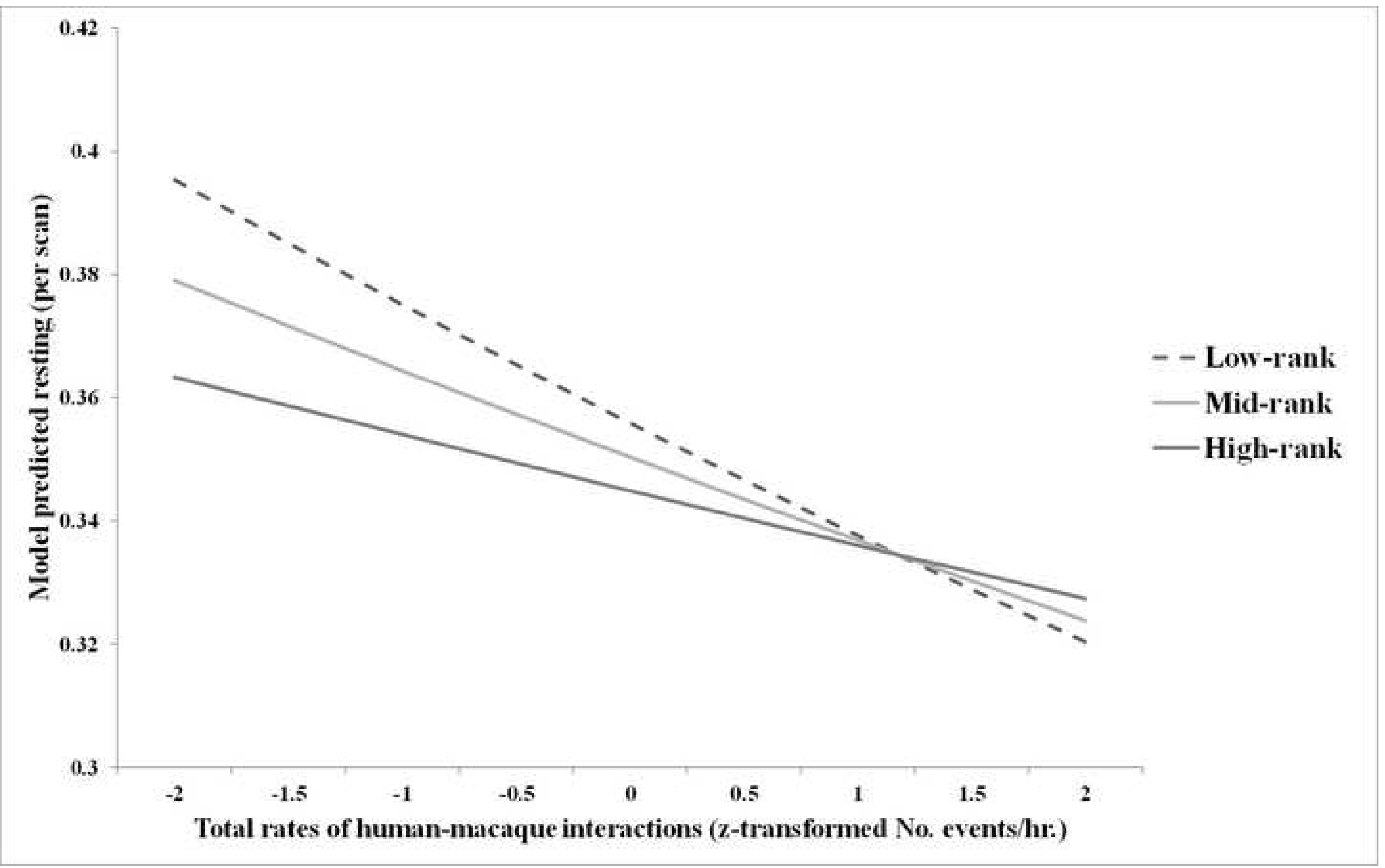

- Mid-rank -High-rank 


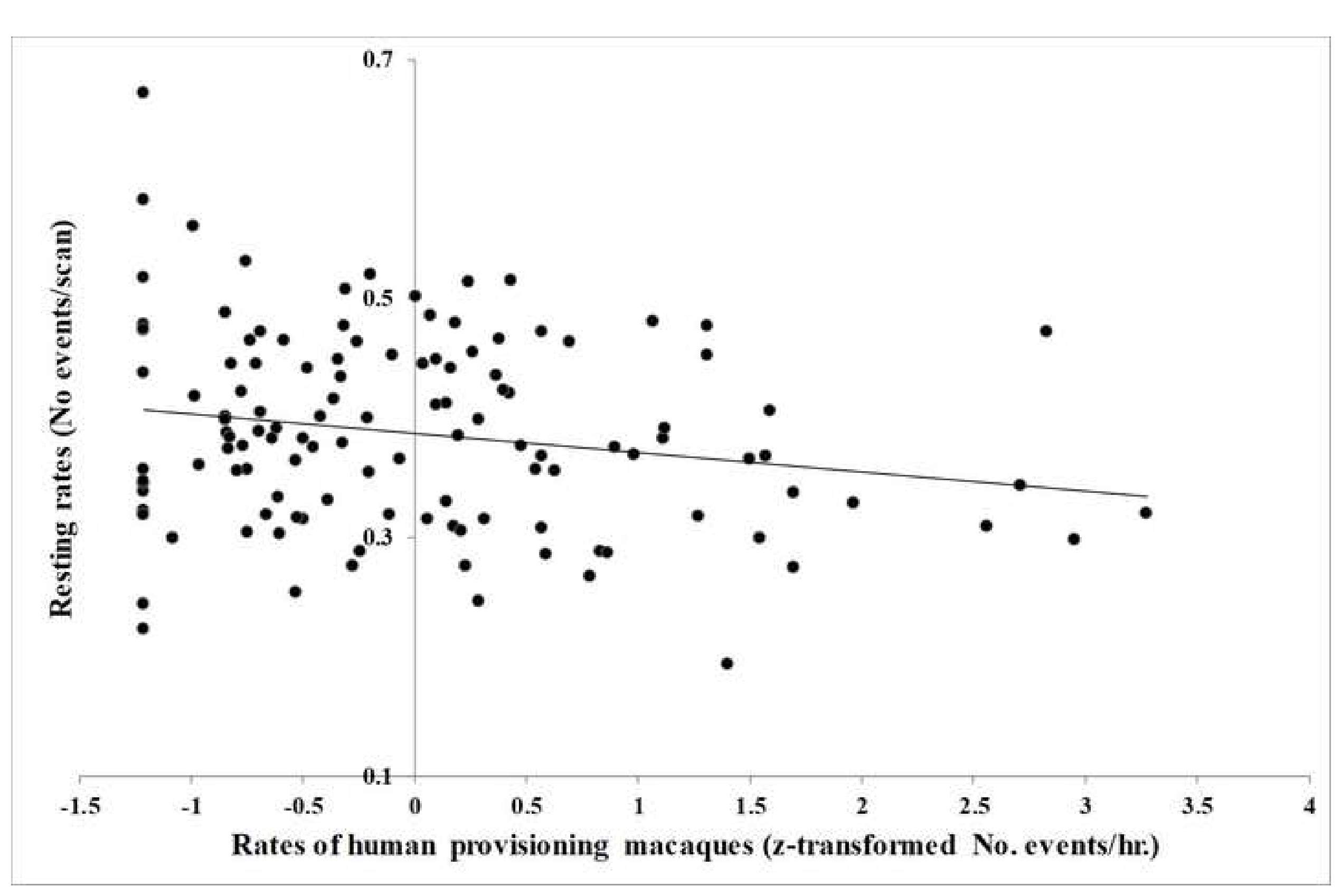



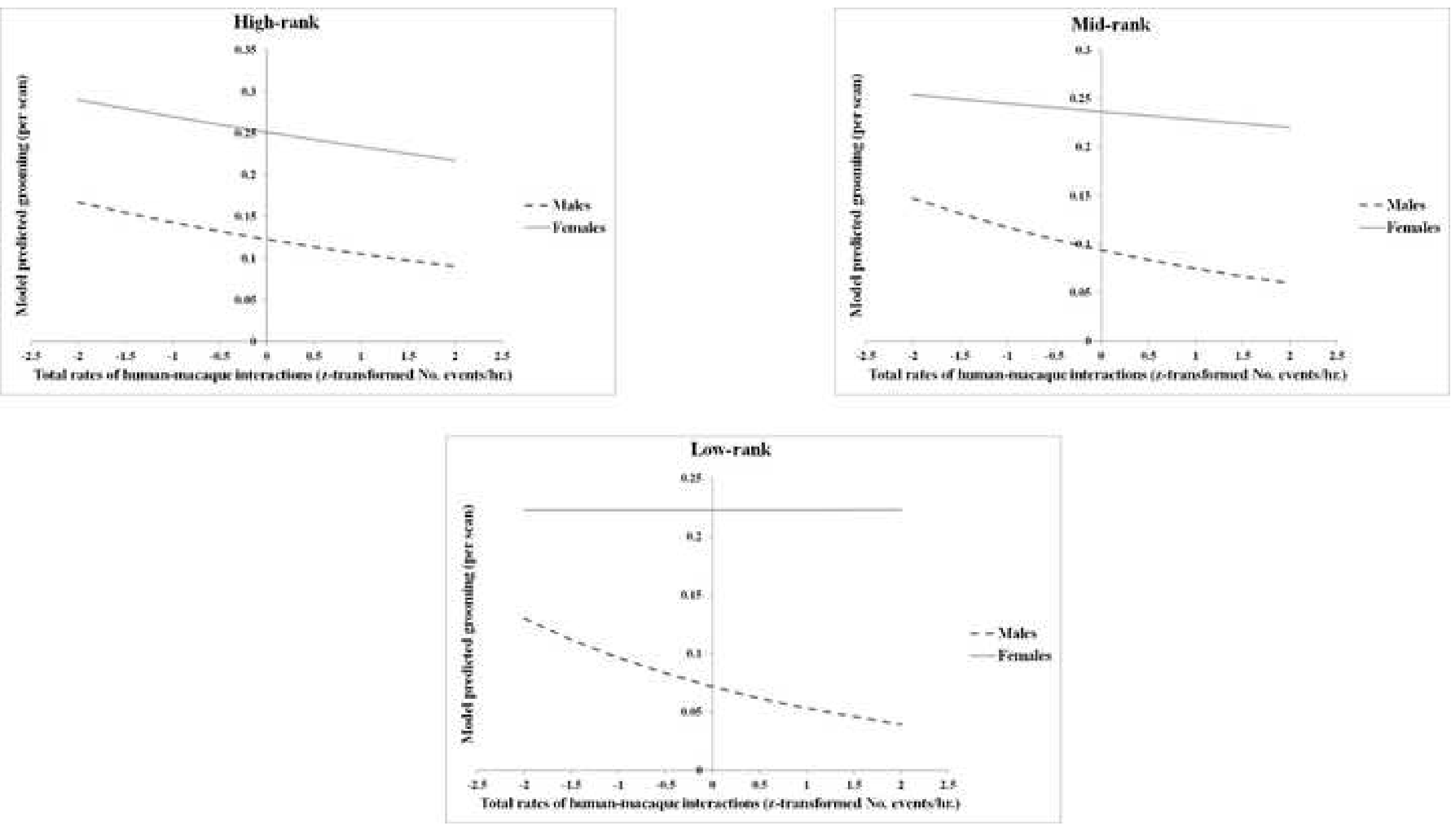